\title{
Lumbar Annular Tear in the Absence of Nerve Root Compression: Is Discectomy Useful?
}

Sir,

The efficacy of discectomy for cases of lumbar annular tear in the absence of nerve root compression is nowadays unclear.

Magnetic resonance imaging (MRI) is established as the investigation of choice in the assessment of patients presenting with low back pain and sciatica. In MRI, annular tears are manifest as hyperintensity zones (HIZs), a focus on a degenerative lumbar intervertebral disc. ${ }^{[1]}$

Herein, we report a case of a 53-year-old woman affected by right lumbar cruralgia and L4-L5 radiculopathy, whose lumbar MRI demonstrated the presence of an HIZ in proximity to the symptomatic nerve root but no clear nerve root compression. After a right L4-L5 microdiscectomy, the patient showed a good recovery.

A review of the literature is reported to evaluate the benefits of microdiscectomy in the presence of annular tear, also in the absence of a clear nerve root compression.
We report a case of a 53-year-old woman affected by right lumbar cruralgia, hypoesthesia associated to weakness at L4-L5 nerve root territories. T2-weighted MRI demonstrated hyperintensity within the right posterior part of L4-L5 intervertebral disc in proximity to the symptomatic nerve root [Figure 1a and $\mathrm{b}$ ], and a homogeneous enhancement was showed at postgadolinium infusion MRI [Figure 2a and $\mathrm{b}$ ]. A clear nerve root compression was not present; nevertheless, we decided to proceed with a right L4-L5 microdiscectomy in view of patient's symptoms. At surgery, there was L4-L5 bulging disc, but the adjacent nerve root was not compressed. We executed an L4-L5 facetectomy to fully visualize it into the intervertebral foramen and no compressions were evident. An interspinous device was applied to reduce the risk of instability after the facetectomy. In the following days, the patient showed a good recovery in terms of pain and neurological symptoms and she was discharged on the $3^{\text {rd }}$ postoperative day. 


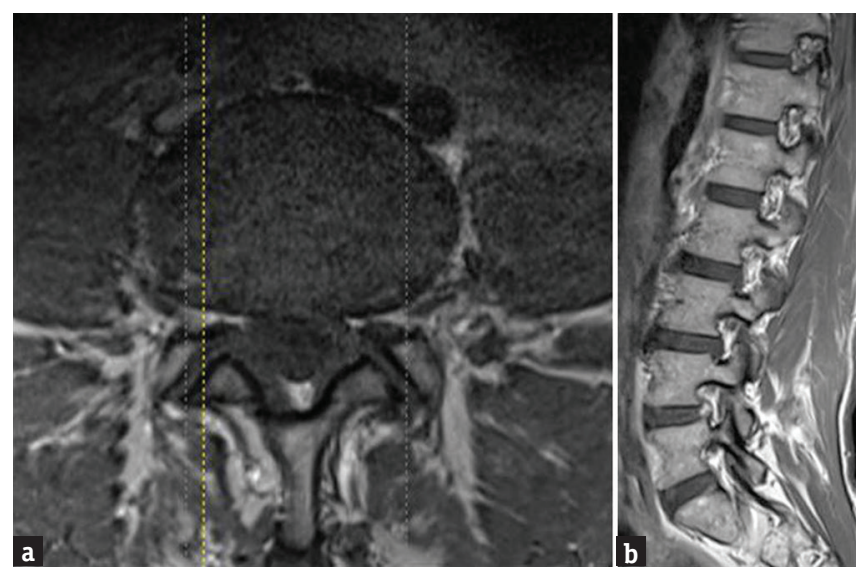

Figure 1: On T2-weighted magnetic resonance imaging, hyperintensity of posterior part of L4-L5 disc was manifested in axial (a) and sagittal images (b)

On postgadolinium lumbar spine MRI, extradural enhancement may be seen in a variety of situations. The margins of herniated disc fragments, extradural extension of vascularized tumor, or extradural abscess will enhance following gadolinium. Benneker et al. studied 39 human lumbar discs (L1-S1) harvested from eight cadavers within $48 \mathrm{~h}$ postmortem using MRI in various spin-echo sequences sectioning in the mid-sagittal plane. He concluded that MRI alterations correlated significantly with $\mathrm{H}_{2} \mathrm{O}$ and proteoglycan content $(P<0.001)$ and were the best for detecting highly degenerated discs. ${ }^{[2]}$ Annulus HIZ is considered by some authors highly specific predictors of chronic low back pain, yet the underlying source of the pain is unclear. ${ }^{[3]}$ Nevertheless, some authors and leaders in back pain field dismiss the value of MRI since people without low back pain presents high rates of MRI findings as HIZ. ${ }^{[4]}$ Dongfeng et al. observed the distribution of tumor necrosis factor-alpha (TNF- $\alpha$ ) and CD68 in the intervertebral disc specimens from 26 patients affected by low back pain whose MRI showed HIZ and in specimens from intervertebral discs of five cadavers. The histological exam of the specimens from HIZ showed proliferated fibroblasts, TNF- $\alpha$ positive cells and some CD68 positive cells; the number of TNF- $\alpha$ and CD68 positive cells in HIZ was significantly higher than in specimens from intervertebral discs of cadavers $(P<0.05)$. They concluded that HIZ is a specific sign of inflammatory reaction. ${ }^{[5]}$ Moon et al. analyzed how annulus fibrosus/ neuron interactions during annular injury were involved in neovascularization and nerve ingrowth. He reported that annulus fibrosus cells involved in inflammatory reaction enhance the production of growth factors responsible for neovascularization and nerve ingrowth. Perhaps, they can indicate an inflammatory reaction. ${ }^{[6]}$ Peng et al. conducted a study on 42 patients with chronic low back pain accompanied by unilateral or bilateral radiating leg pain but without lumbar disc herniation on computed tomography and MRI. He treated the patients with anterior lumbar interbody fusion, posterior lumbar interbody fusion, or prosthetic nucleus pulposus displacement through the anterior retroperitoneal approach in one. He concluded that symptoms such as low

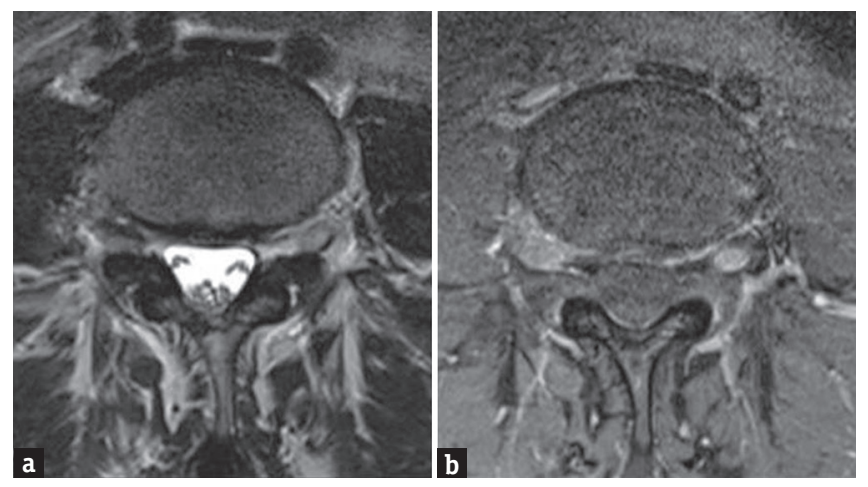

Figure 2: lumbar magnetic resonance imaging after gadolinium infusion demonstrated a homogeneous enhancement of L4-L5 disc and adjacent nerve root (a) before and (b) after gadolinium infusion

back pain or sciatica in these cases could be explained by the irritating effects of chemical mediators produced by nucleus pulposus leaking through annular tears. ${ }^{[7]}$

Our case demonstrates how lumbar disc flogosis can cause an irritating effect on the adjacent nerve root determining sciatica and nerve root dysfunctions. We believe that the presence of these symptoms, also in the absence of a clear nerve root compression, can be considered indication for microdiscectomy with the aim to solve the "chemical" reaction on the adjacent nerve root.

\section{Acknowledgments}

We thank the patient for giving us the consent to this study.

\section{Financial support and sponsorship}

Nil.

\section{Conflicts of interest}

There are no conflicts of interest.

\section{Lorenzo Nigro, Alessandro Landi, Nicola Marotta, Roberto Delfini}

Department of Neurology and Psychiatry, Neurosurgical Division, University of Rome "Sapienza" Policlinico Umberto I, Rome,

Italy

Address for correspondence: Dr. Lorenzo Nigro, Department of Neurology and Psychiatry, Neurosurgical Division, University of Rome "Sapienza" Policlinico Umberto I, Viale dell'Università 00125 Rome, Italy. E-mail: nigro86@hotmail.it

\section{REFERENCES}

1. Saifuddin A, Mitchell R, Taylor BA. Extradural inflammation associated with annular tears: Demonstration with gadolinium-enhanced lumbar spine MRI. Eur Spine J 1999;8:34-9.

2. Benneker LM, Heini PF, Anderson SE, Alini M, Ito $\mathrm{K}$. Correlation of radiographic and MRI parameters to morphological and biochemical assessment of intervertebral disc degeneration. Eur Spine J 2005;14:27-35.

3. Sheng WB, Guo HL, Mai ED, Pu LT, Zhan YL, Jin GL, et al. Clinical characteristics and treatment for patients with low back 
and leg pain caused by lumbar annular tears. Zhonghua Yi Xue Za Zhi 2010;90:3198-202.

4. Hancock M, Maher C, Macaskill P, Latimer J, Kos W, Pik J. MRI findings are more common in selected patients with acute low back pain than controls? Eur Spine J 2012;21:240-6.

5. Dongfeng R, Hou S, Wu W, Wang H, Shang W, Tang J, et al. The expression of tumor necrosis factor-a and CD68 in high-intensity zone of lumbar intervertebral disc on magnetic resonance image in the patients with low back pain. Spine (Phila $\mathrm{Pa}$ 1976) 2011;36:E429-33.

6. Moon HJ, Kim JH, Lee HS, Chotai S, Kang JD, Suh JK, et al. Annulus fibrosus cells interact with neuron-like cells to modulate production of growth factors and cytokines in symptomatic disc degeneration. Spine (Phila Pa 1976) 2012;37:2-9.

7. Peng B, Hou S, Wu W, Zhang C, Yang Y. The pathogenesis and clinical significance of a high-intensity zone (HIZ) of lumbar intervertebral disc on MR imaging in the patient with discogenic low back pain. Eur Spine J 2006;15:583-7.
This is an open access article distributed under the terms of the Creative Common Attribution-NonCommercial-ShareAlike 3.0 License, which allows others to remix, tweak, and build upon the work non-commercially, as long as the author is credited and the new creations are licensed under the identical terms.

\begin{tabular}{|l|l|}
\hline \multicolumn{2}{|c|}{ Access this article online } \\
\hline Quick Response Code: & Website: \\
\hline & www.ruralneuropractice.com \\
\cline { 2 - 2 } & \\
& \\
\end{tabular}

How to cite this article: Nigro L, Landi A, Marotta N, Delfini R. Lumbar annular tear in the absence of nerve root compression: Is discectomy useful?. J Neurosci Rural Pract 2016;7:S126-8. 